\title{
Resubmission Letter
}

National Cancer Institute

\section{Source}

National Cancer Institute. Resubmission Letter. NCI Thesaurus. Code C126071.

An alphabetic character that describes the incremental order of trial submissions or resubmissions. 